\title{
EFFECT OF NURSING CARE GUIDELINES FOR PRESSURE ULCERS PREVENTION TO ORTHOPEDIC IMMOBILIZED PATIENTS \\ ${ }^{1}$ Asmaa Mohammed Mohammed, ${ }^{2}$ Walaa Nasreldin Othman, ${ }^{3}$ Wafaa Ismail Shereif \\ 1,2,3Medical-Surgical Nursing Department, Faculty of Nursing, Mansoura University, Egypt E-mail of corresponding author: smsm4912@gmail.com
}

\begin{abstract}
Background: Pressure ulcers are common health problems that represent a nursing and social burden. Mortality risk in a patient with pressure ulcer is 2 to 6 times greater than this in a patient with intact skin. The Aim of the study is to evaluate the effect of implementing nursing care guidelines for pressure ulcers prevention to orthopedic immobilized patients. Method: Quasi-experimental research design was used to conduct this study in orthopedic unit at Mansoura Emergency Hospital. The sample of this study was consisted of 74 patients, divided into study and control groups equally. Results and Conclusion: There was statistically significant difference between the study and control groups regarding post-implementation of pressure ulcer prevention guidelines. Recommendations: Nursing care guidelines for prevention of pressure ulcers should effectively be implemented for orthopedic immobilized patients who are assessed as being at pressure ulcers risk.
\end{abstract}

Key words: Nursing Care Guidelines, Orthopedic Immobilized, Pressure Ulcers, Prevention.

\section{Introduction:}

Pressure ulcer (PU) is a major problem distressing both hospitalized patients and community populations (Coleman et al., 2013). It has been reported that up to $28 \%$ in-patients experience pressure ulcers anywhere (Levine et al., 2013). Pressure ulcer is one of the most significant clinical issues related to patient safety and service quality; it is considered an indicator of care quality and has a significant, negative effect on patients, care staff, and healthcare costs. However, PU has been estimated the $5^{\text {th }}$ most common cause of potentially preventable hospitalizations (Kwong et al., 2016).

In spite of efforts done to prevent pressure ulcer, it is still common problem. It is estimated that nearly 700,000 patients yearly developed PUs in the UK. Nearly 186,617 in-patients annually had a new pressure ulcer in acute care sitting. Up to
$6 \%$ of individuals in acute care settings and more than $10 \%$ in non-acute care developed PUs. However, PUs are blamed for about $2 \%$ of avoidable deaths (Durkin \& May, 2015).

Pressure ulcer defined as a confined damage of a certain area of the skin and soft tissues owing to the external pressure, resulting in the necrosis of the ischemic area (Tsaras et al., 2016). The occurrence of PUs is highly attached to the ability of patients to move and reposition themselves, the main contributing factors are immobility and comorbidities (Coleman et al., 2013).

Chronic conditions including diabetes and vascular disease can slow down blood flow causing pressure ulcers. Bladder disorders that lead to incontinence also increase risk factor for pressure ulcers, because dampness to the skin for long periods of time will 
accelerate break down to the skin. In addition, nutritional deficiency can also lead to pressure ulcer development (Bry et al., 2012).

Pressure ulcers represent a devastating complication in the care of orthopedic patients. Morbidity and mortality rates are higher in orthopedic patients who developed PUs than patients who remain pressure ulcers free. The incidence of pressure ulcer in patients undergoing hip fracture repair only is as high as $42 \%$ of hospitalization (Jaeblon, 2010).

Several guidelines for the prevention of pressure ulcers were developed, which all are centered on knowing and implementing relatively simple interventions that can be used universally (de Oliveira Matos et al., 2017). Interventions for prevention of PUs include various support surfaces, repositioning, adequate nutrition and skin care. Preventive nursing care will be adapted according to the care setting or patient characteristics. For patient who is undernourished, nutritional supplementation will be of greater benefit. While for patient with incontinence, skin care will be of greater benefit. Some interventions that involve specialized equipment or substantial nursing resources may be less feasible for community settings (Ratliff $\boldsymbol{e t}$ al., 2010).

\section{Significance of the study}

Previous studies revealed prevalence rates of between $13.9 \%$ - 29\%, among individuals within orthopedic settings indicating that PUs are major problems within the orthopedic units (Moore \& Dealey, 2014). Studies on pressure ulcer prevention guidelines are rarely done at Mansoura Emergency Hospital, in spite of increased numbers of beds occupied by orthopedic patients suffering from pressure ulcers. So, the current study was aimed to evaluate the effect of nursing care guidelines on prevention of pressure ulcers for orthopedic immobilized patients at Mansoura Emergency Hospital.

Aim of the Study

The study was aimed to evaluate the effect of implementing nursing care guidelines for pressure ulcers prevention to orthopedic immobilized patients at Mansoura Emergency Hospital.

Research hypothesis

Pressure ulcers will be prevented in orthopedic immobilized patients who will receive nursing care guidelines in comparison to orthopedic immobilized patients who will receive routine nursing care.

\section{Subjects and Method \\ Research design}

Quasi-experimental research design was utilized to conduct this study.

\section{Setting}

This study was conducted in orthopedic department of Emergency Hospital at Mansoura University Hospitals.

\section{Subjects}

A purposive sample of 74 patients from both sex and were admitted to the above mentioned setting involved in this study, all the subjects were randomly assigned into two equal groups, the first group (control group) including 37 patients received only routine nursing care for prevention of pressure ulcers, the Second group (study group) also including 37 patients but received the nursing care guidelines for prevention of pressure ulcers.

\section{Tools of data collection}

The researcher used two tools for data collection:

\section{Tool (I): Comprehensive skin} assessment sheet.

This tool has been developed by the researcher after passing a broad and relevant review of literature. This tool consisted of three main parts: Part I "Socio-demographic characteristics of patients", Part II "Medical history" and 
Part III "Comprehensive skin assessment pre and post-guidelines implementation".

Tool (II): Braden Risk Assessment

Scale.

The Braden Scale was developed by (Bergstrom, Braden, Laguzza \& Holman, 1987). It has been used to evaluate the patient's level of risk to develop PUs. This scale is a brief assessment scale consisting of six subscales; sensory perception, skin moisture, activity, mobility, nutrition, and friction/shear.

\section{Method}

- Ethical approval was obtained from Research Ethics Committee at the Faculty of Nursing - Mansoura University. An official approval for conducting the study obtained from the director and head of Orthopedic Department at Mansoura Emergency Hospital.

- Tool I was tested for its validity by a jury composed of five experts from Faculty of Nursing-Mansoura University and necessary modifications were done.

- A pilot study was conducted on $10 \%$ of patients $(n=8)$ who were not included in the actual study sample to ensure the clarity and applicability of all items of the tools and all necessary modifications were done.

- The researcher collected data over a period of five months from February 1, 2017 to June 30, 2017. The study participants were assigned randomly into the study and control groups. The first 37 patients considered as control group, the next 37 patients constituted the study group.

The data collection was carried out through four phases:

1. Assessment phase:

During this phase data was collected from both groups regarding patients' profile using tool I (comprehensive skin assessment sheet) to assess socio- demographic characteristics, medical history, and skin characteristics. The researcher excluded patients who were already suffering from pressure ulcers on initial skin assessment, and also using tool II (Braden Risk Assessment Scale) that was utilized daily for one week. This phase take about 20-25 minutes.

\section{Preparation phase:}

During this phase the researcher prepared the environment and supplies which needed for prevention of pressure ulcers for the study group, also, patients' consent was taken from them during this phase.

3. Nursing care guidelines implementation phase:

During this phase the researcher implemented nursing care guidelines which adapted from (National Pressure Ulcer Advisory Panel, European Pressure Ulcer Advisory Panel and Pan Pacific Pressure Injury Alliance. 2014) to prevent pressure ulcers for the study group only. Nursing care guidelines included instructional points (was taught in one session and took about 30 - 35 minutes) and practical points (carried out for about 3-5 patients individually and repeated daily for one week).

\section{Evaluation phase:}

During this phase the researcher reassessed each patient in the study and control groups using part III of tool I (comprehensive skin assessment) and evaluated the effect of implementing nursing care guidelines on prevention of pressure ulcers for study group and effect of routine nursing care for control group.

\section{Statistical analysis:}

All statistical analyses were performed using SPSS for windows version 20.0 (SPSS, Chicago, IL). Data were tested for normality of distribution prior to any calculations. Continuous data were expressed in mean and standard deviation while categorical data were expressed in number and percentage. The comparisons were determined using Student's t test for 
variables with continuous data. Chisquare test was used for comparison between variables with categorical data. Statistical significance was set at $\mathrm{p}<0.05$.

\section{Results}

Table (1) Shows comparison between the study and control groups as regards to comprehensive skin assessment preguidelines implementation. Regarding skin temperature, more than half $(62.2 \%$

Table 1. Comparison between the Study and Control Groups According to Comprehensive Skin Assessment Pre-Guidelines Implementation

\begin{tabular}{|c|c|c|c|c|c|c|}
\hline \multirow[t]{2}{*}{ Variables } & \multicolumn{2}{|c|}{ Study group } & \multicolumn{2}{|c|}{ Control group } & \multicolumn{2}{|c|}{ Chi square test } \\
\hline & $\begin{array}{l}\mathrm{N} \\
37\end{array}$ & $\%$ & $\begin{array}{l}\mathrm{N} \\
37\end{array}$ & $\%$ & $\mathrm{X} 2$ & $\mathrm{P}$ \\
\hline \multicolumn{7}{|l|}{ Temperature } \\
\hline Normal & 14 & $37.8 \%$ & 17 & $45.9 \%$ & & \\
\hline Localized heat & 23 & $62.2 \%$ & 20 & $54.1 \%$ & 0.500 & 0.480 \\
\hline \multicolumn{7}{|l|}{ Color } \\
\hline Pink & 16 & $43.2 \%$ & 16 & $43.2 \%$ & & \\
\hline Pallor & 21 & $56.8 \%$ & 21 & $56.8 \%$ & 0 & 1.000 \\
\hline \multicolumn{7}{|l|}{ Moisture } \\
\hline Moist & 21 & $56.8 \%$ & 24 & $64.9 \%$ & & \\
\hline Excessive moist & 16 & $43.2 \%$ & 12 & $32.4 \%$ & & \\
\hline Dry & 0 & $0.0 \%$ & 1 & $2.7 \%$ & 1.771 & 0.412 \\
\hline \multicolumn{7}{|l|}{ Turgor } \\
\hline Normal (<3 sec.) & 30 & $81.1 \%$ & 31 & $83.8 \%$ & & \\
\hline Impaired (>3 sec.) & 7 & $18.9 \%$ & 6 & $16.2 \%$ & 0.093 & 0.760 \\
\hline \multicolumn{7}{|l|}{ Tissue perfusion } \\
\hline $\begin{array}{l}\text { Normal } \\
\text { (Capillary refill time < } \\
3 \text { sec.) }\end{array}$ & 21 & $56.8 \%$ & 22 & $59.5 \%$ & & \\
\hline $\begin{array}{l}\text { Decreased (Capillary } \\
\text { refill time }>3 \mathrm{sec} .)\end{array}$ & 16 & $43.2 \%$ & 15 & $40.5 \%$ & 0.056 & 0.814 \\
\hline \multicolumn{7}{|l|}{ Integrity } \\
\hline Intact & 37 & $100 \%$ & 37 & $100 \%$ & 0 & 1.000 \\
\hline
\end{tabular}

Table (2) Illustrates comparison between the study and control groups according to Braden risk assessment scale total score. At the $3^{\text {rd }}$ day mean score and SD were $(13.9 \pm 1.6$ vs. $12.9 \pm 2.0)$ in study and control groups respectively, with statistically significant difference $(\mathrm{P}=$ vs. $54.1 \%$ ) of the study and control groups respectively had localized heat. As regard to skin color, more than half $(56.8 \%)$ of both study and control group had pallor skin. According to skin integrity, all participants in study and control group $(100 \%)$ had intact skin. No significant difference was detected between the two groups, where (p-value > $0.05)$. 
Table 2. Comparison between the Study and Control Group According to Braden Risk Assessment Scale Regarding Total Score

\begin{tabular}{|c|c|c|c|c|c|c|}
\hline \multirow[t]{2}{*}{ Variables } & \multicolumn{2}{|c|}{ Study groups } & \multicolumn{2}{|c|}{ Control groups } & \multicolumn{2}{|c|}{ Chi square test } \\
\hline & $\begin{array}{l}\mathbf{N} \\
37\end{array}$ & $\%$ & $\begin{array}{l}\mathbf{N} \\
37\end{array}$ & $\%$ & $\mathbf{X}^{2}$ & $\mathbf{P}$ \\
\hline \multicolumn{7}{|l|}{ Third day } \\
\hline Mild risk & 15 & $40.5 \%$ & 8 & $21.6 \%$ & & \\
\hline Moderate risk & 13 & $35.1 \%$ & 14 & $37.8 \%$ & & \\
\hline High risk & 9 & $24.3 \%$ & 15 & $40.5 \%$ & 3.667 & 0.160 \\
\hline Range & \multicolumn{2}{|c|}{$11-16$} & \multicolumn{2}{|c|}{$10-17$} & & \\
\hline Mean \pm SD & \multicolumn{2}{|c|}{$13.9 \pm 1.6$} & \multicolumn{2}{|c|}{$12.9 \pm 2.0$} & 2.363 & $0.021^{* \wedge}$ \\
\hline \multicolumn{7}{|l|}{ Fourth day } \\
\hline Mild risk & 22 & $59.5 \%$ & 7 & $18.9 \%$ & & \\
\hline Moderate risk & 14 & $37.8 \%$ & 12 & $32.4 \%$ & & \\
\hline High risk & 1 & $2.7 \%$ & 18 & $48.6 \%$ & 23.123 & $<0.001 * *$ \\
\hline Range & \multicolumn{2}{|c|}{$12-17$} & \multicolumn{2}{|c|}{$10-18$} & & \\
\hline Mean \pm SD & \multicolumn{2}{|c|}{$14.7 \pm 1.2$} & \multicolumn{2}{|c|}{$12.6 \pm 1.9$} & 5.756 & $<0.001 * * \wedge$ \\
\hline \multicolumn{7}{|l|}{ Fifth day } \\
\hline Mild risk & 30 & $81.1 \%$ & 4 & $10.8 \%$ & & \\
\hline Moderate risk & 5 & $13.5 \%$ & 14 & $37.8 \%$ & & \\
\hline High risk & 2 & $5.4 \%$ & 19 & $51.4 \%$ & 37.907 & $<0.001 * *$ \\
\hline Range & \multicolumn{2}{|c|}{$11-18$} & \multicolumn{2}{|c|}{$10-18$} & & \\
\hline Mean \pm SD & \multicolumn{2}{|c|}{$15.4 \pm 1.4$} & \multicolumn{2}{|c|}{$12.6 \pm 1.7$} & 7.807 & $<0.001 * * \wedge$ \\
\hline \multicolumn{7}{|l|}{ Sixth day } \\
\hline Mild risk & 32 & $86.5 \%$ & 3 & $8.1 \%$ & & \\
\hline Moderate risk & 4 & $10.8 \%$ & 12 & $32.4 \%$ & & \\
\hline High risk & 1 & $2.7 \%$ & 22 & $59.5 \%$ & 47.202 & $<0.001 * *$ \\
\hline Range & \multicolumn{2}{|c|}{$12-18$} & \multicolumn{2}{|c|}{$9-18$} & & \\
\hline Mean \pm SD & \multicolumn{2}{|c|}{$15.9 \pm 1.4$} & \multicolumn{2}{|c|}{$12.4 \pm 1.8$} & 9.417 & $<0.001 * * \wedge$ \\
\hline \multicolumn{7}{|l|}{ Seventh day } \\
\hline Mild risk & 32 & $86.5 \%$ & 5 & $13.5 \%$ & & \\
\hline Moderate risk & 4 & $10.8 \%$ & 10 & $27.0 \%$ & & \\
\hline High risk & 1 & $2.7 \%$ & 22 & $59.5 \%$ & 41.448 & $<0.001 * *$ \\
\hline Range & \multicolumn{2}{|c|}{$12-18$} & \multicolumn{2}{|c|}{$9-18$} & & \\
\hline Mean \pm SD & \multicolumn{2}{|c|}{$16.0 \pm 1.3$} & \multicolumn{2}{|c|}{$12.4 \pm 1.9$} & 9.256 & $<0.001 * * \wedge$ \\
\hline
\end{tabular}

(*) Statistically significant at $P \leq 0.05 \quad\left({ }^{\wedge}\right)$ P value based on student's $t$ test

(**) Highly significant at $\mathbf{P}<\mathbf{0 . 0 0 1}$ 
Figure (1) Illustrates that, more than half $(62.2 \%$ vs. $54.1 \%)$ of the study and control groups respectively had localized heat pre-guidelines implementation with no statistically significant difference $(p>0.05)$. While, more than one quarter

Figure 1. Comparison between the Study and Control Groups Regarding Skin

Temperature Pre and Post-guidelines Implementation $n=(37$ study \& 37 control).

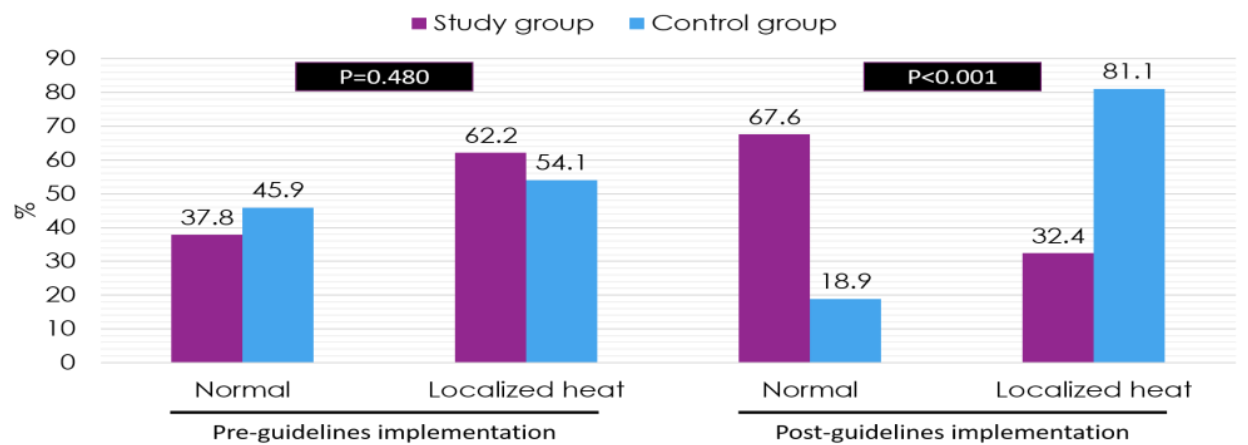

Figure (2) Shows that, more than half $(56.8 \%$ vs. $64.9 \%)$ of the study and control groups respectively had moist skin pre-guidelines implementation with no statistically significant difference ( $p>0.05)$. on the other hand, the majority
$(32.4 \%)$ of the study group and more than three quarter $(81.1 \%)$ of the control group had localized heat post-guidelines implementation with highly statistical significant difference $(\mathrm{p}<0.001)$.

Figure 2. Comparison between the study and control groups regarding skin moisture pre and post-guidelines implementation $n=(37$ study \& 37 control).

- Study group = Control group

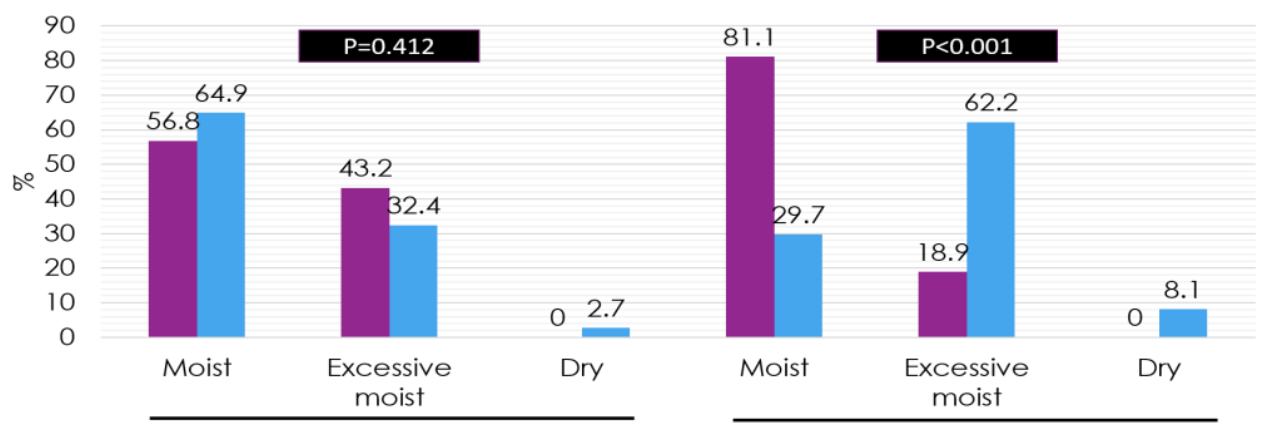

Pre-guidelines implementation

Post-guidelines implementation

Figure (3) Clarifies that, no one of the participant in the studied groups had pressure ulcer pre-guidelines implementation compared by $(2.7 \%$ \&

$29.7 \%$ ) in the study and control groups consecutively significant difference $(\mathrm{p}=0.002)$ 
Figure 3. Comparison between the Study and Control Groups Regarding Skin Integrity Pre and Post-guidelines Implementation $n=(37$ Study \& 37 Control).

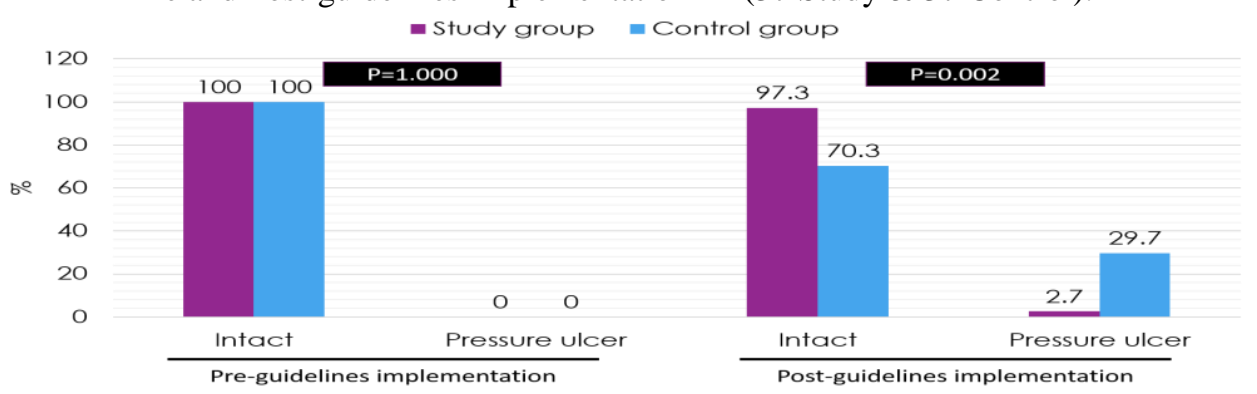

Table (3) Demonstrates Comparison between the study and control groups according to pressure ulcer. It shows that, there was statistically significant

difference between the study and control groups regarding pressure ulcer stage and exposed tissue, at ( $\mathrm{p}$-value $=0.007$ ).

Table 3. Comparison between the Study and Control Groups According to Pressure Ulcer.

\begin{tabular}{|c|c|c|c|c|c|c|}
\hline \multirow[t]{2}{*}{ Variables } & \multicolumn{2}{|c|}{ Study group } & \multicolumn{2}{|c|}{ Control group } & \multicolumn{2}{|c|}{ Chi square test } \\
\hline & $\begin{array}{l}\mathbf{N} \\
\mathbf{3 7}\end{array}$ & $\%$ & $\begin{array}{l}\mathbf{N} \\
\mathbf{3 7}\end{array}$ & $\%$ & $\mathbf{X} 2$ & $\mathbf{P}$ \\
\hline \multicolumn{7}{|l|}{ Pressure ulcer } \\
\hline Yes & 1 & $2.7 \%$ & 11 & $29.7 \%$ & & \\
\hline No & 36 & $97.3 \%$ & 26 & $70.3 \%$ & 9.946 & $0.002 *$ \\
\hline \multicolumn{7}{|l|}{ Location } \\
\hline Coccyx & 0 & $0.0 \%$ & 1 & $9.1 \%$ & & \\
\hline Buttocks & 1 & $100.0 \%$ & 9 & $81.8 \%$ & & \\
\hline Several Sites & 0 & $0.0 \%$ & 1 & $9.1 \%$ & 0.218 & 0.897 \\
\hline \multicolumn{7}{|l|}{ Stage } \\
\hline $\mathrm{I}$ & 1 & $100.0 \%$ & 0 & $0.0 \%$ & & \\
\hline II & 0 & $0.0 \%$ & 5 & $45.5 \%$ & & \\
\hline III & 0 & $0.0 \%$ & 2 & $18.2 \%$ & & \\
\hline IV & 0 & $0.0 \%$ & 4 & $36.4 \%$ & 12.000 & $0.007 *$ \\
\hline \multicolumn{7}{|l|}{ Exposed tissue } \\
\hline Epidermis & 1 & $100.0 \%$ & 0 & $0.0 \%$ & & \\
\hline Dermis & 0 & $0.0 \%$ & 5 & $45.5 \%$ & & \\
\hline subcutaneous tissue & 0 & $0.0 \%$ & 2 & $18.2 \%$ & & \\
\hline fascia/muscles & 0 & $0.0 \%$ & 4 & $36.4 \%$ & 12.000 & $0.007 *$ \\
\hline \multicolumn{7}{|l|}{ Exudate } \\
\hline None & 1 & $100.0 \%$ & 3 & $27.3 \%$ & & \\
\hline Mild & 0 & $0.0 \%$ & 4 & $36.4 \%$ & & \\
\hline Moderate & 0 & $0.0 \%$ & 4 & $36.4 \%$ & $2.182 \mathrm{a}$ & 0.336 \\
\hline \multicolumn{7}{|l|}{ Oder } \\
\hline Absent & 1 & $100.0 \%$ & 7 & $63.6 \%$ & & \\
\hline Present & 0 & $0.0 \%$ & 4 & $36.4 \%$ & 0.545 & 0.460 \\
\hline
\end{tabular}

(*) Statistically significant at $P \leq 0.05$

(**) Highly significant at $\mathbf{P}<\mathbf{0 . 0 0 1}$ 


\section{Discussion:}

Pressure ulcers described not only as one of the most expensive and physically devastating complications, but also considered the third most costly disorder following cancer and cardiovascular diseases. Each year, above one million patients have PUs, Moreover nearly $57 \%$ to $60 \%$ of all pressure ulcers develop within hospitals. Avoidance is usually rated as the most effective way to reduce pressure ulcer development (Alhosis et al., 2012).

In the current study patients were assessed for being at risk of developing pressure ulcer using Braden Risk Assessment Scale (BRAS). According to Braden risk assessment subscales regarding moisture, it was noted that, there was no statistically significant difference between the study and control groups on $1^{\text {st }} \& 2^{\text {nd }}$ day, while there was statistically significant difference between both groups on $3^{\text {rd }}$ day, and highly statistical significant difference between two groups at $4^{\text {th }}-7^{\text {th }}$ day.

This finding is supported by the study of Yusuf et al. (2015) who revealed that, regarding moisture subscale; there was statistically significant difference between the group who developed pressure ulcer and those who did not. This can be attributed to the effect of applying preventive skin care for the study group that kept skin clean and dry. This result came in contrast with Cox (2011) as he pointed out that, scores of moisture subscale weren't predictive for PUs development, possible explanation for this finding in his study was the regular use of indwelling devices that minimized skin exposure to dampness from two main sources: from urine (using indwelling urinary catheters) and from liquid stool (using fecal containment devices).

Regarding Braden mobility subscale, the findings from this study showed that, there was statistically significant difference between the study and control groups at $4^{\text {th }} \& 5^{\text {th }}$ day consecutively. Highly statistical significant difference was found between both groups at $6^{\text {th }} \& 7^{\text {th }}$ day. This finding is similar to (Krapfl \& Gray, 2008) who stated that, moving and changing position of immobilized patients is a key principle of nursing interventions and has high priority in all current clinical guidelines to avoid PUs. Our study finding can be explained by that, the use of manual moving and handling aids help the patients to lift and reposition themselves where mobility on Braden scale defined as ability to change and control body position.

In relation to Braden nutrition subscale, the present study pointed out that, there was statistically significant difference between two groups at $4^{\text {th }}$ day, and also highly statistical significant difference between two groups at $5^{\text {th }}-7^{\text {th }}$ day. This finding came in the same line with Cox (2011) who reported that, although the Braden nutrition subscale scores were correlated to the occurrence of PUs in his study, these scores were insignificant; similarly, Yusuf et al. (2015) stated that, regarding nutrition, there was statistically significant difference between those who developed PUs and those who continued free from such ulcers. Our study finding may be related to the effect of hypoalbuminemia that resulted from inadequate protein and caloric intake which in turn increase risk for pressure ulcer development.

According to Braden friction and shear subscale, the present study pointed out that, there was statistically significant difference between the study and control groups at $3^{\text {rd }} \& 4^{\text {th }}$ day, and highly statistical significant difference at $5^{\text {th }}-7^{\text {th }}$ day. This finding supported by Cox (2011) who revealed that pressure 
ulcer was approximately six times more probably to develop in individuals who had more exposure to friction/shear than in those who had little exposure.

This finding is also in agreement with Yusuf et al. (2015) who found that, regarding friction and shear, there was significant difference between those who developed PUs and those who continued free from such ulcers. This finding can be attributed to using manual handling aids and proper application of moving and repositioning procedures to the patients which minimize the forces of friction and shear on the skin.

Regarding BRAS total score, there was significant difference between the study and control groups on the $3^{\text {rd }}$ day, and highly significant difference at the $7^{\text {th }}$ day. This finding is in agreement with Atyea, Mohamed, Mohammed \& Abdel Aziz (2013), whose study indicated that, on the day of admission, there was no significant difference between the study and control groups, but there was significant difference at $2^{\text {nd }}$ to $4^{\text {th }}$ day. There was moderate significant difference at $5^{\text {th }}$ to $6^{\text {th }}$ day then there was highly significant difference at $7^{\text {th }}$ day. Furthermore, This finding is coincide with Yusuf et al. (2015), who revealed that the mean BRAS score was low in patients who had PUs compared with those who remained free from ulcers.

According to comprehensive skin assessment regarding temperature, the study pointed out that, more than half of the study and control groups respectively had localized heat preguidelines implementation. While more than one quarter of the study group and more than three quarter of the control group had localized heat post-guidelines implementation, with highly statistical significant difference. This finding is in agreement with Yusuf et al. (2015) who stated that PU development can be predicted by localized heat of the skin.
They found slight significant differences in total skin temperature in the group who developed pressure ulcers and this who did not. This can be explained by that, using standard hospital mattresses that have plastic coverings, can accumulate heat between patients' skin and mattresses.

Regarding skin integrity, it was found that, pressure ulcers occurred in (2.7\% vs. $29.7 \%)$ of the study and control groups respectively at the $7^{\text {th }}$ day, which is affected by implementation of nursing care guidelines in the study group. This result is supported by Campbell, Woodbury \& Houghton (2010) who mentioned that incidence of PUs after the implementation of the preventive program was statistically significant compared to the pre-intervention incidence.

In the same line, the study done by Atyea, Mohamed, Mohammed \& Abdel Aziz (2013) revealed that, (3.3\% vs. $27 \%$ ) of the study and control groups respectively had pressure ulcer in the $7^{\text {th }}$ day of the study. Furthermore, AlShadedi (2012) reported that, the prevalence rate of pressure ulcers in his study was $27.90 \%$. This similarity between the results might be due to similarity in preventive nursing care.

\section{Conclusion}

The main conclusion which was drawn from the present study is that implementation of nursing care guidelines was highly effective in preventing and decreasing the severity of pressure ulcers for orthopedic immobilized patients. On the other hand, orthopedic immobilized patients who received routine nursing care developed several and higher stages of pressure ulcers.

\section{Recommendations}

Based on the current study findings; it is recommended that:

- Periodic assessment of orthopedic immobilized patients should be done using risk assessment scale. 
- Preventive interventions that include skin care, nutrition, movement, and position-change should effectively be implemented in cooperation with the patients who are assessed as being at pressure ulcer risk.

- Further study or research to recognize barriers regarding the implementation of pressure ulcer preventive measures is needed.

- Nursing care guidelines for pressure ulcers prevention should be applied to larger sample and different governmental hospital for generalization.

Acknowledgement

Special thanks from the author to the participant in the current study, thanks also to hospital coordinators.

\section{References}

1. Al-Shadedi, A. M. (2012). Prevalence of pressure ulcers in orthopaedic patients. Iraq. Postgrad. Med. J, 11, 529-535.

2. Atyea, A., Mohamed, R., Mohammed M. \& Abdel Aziz, M. (2013). The effect of nursing guidelines for preventing pressure ulcer in intensive care units on patients outcomes. AAMJ, 10(3), 179-206.

3. Bergstrom, N., Braden, B., Laguzza, A., Holman, V. (1987). The Braden Scale for Predicting Pressure Sore Risk. Nurs Res, 36, 205-21.

4. Bry, K. E., Buescher, D., \& Sandrik, M. (2012). Never say never: A descriptive study of hospital-acquired pressure ulcers in a hospital setting. Journal of Wound Ostomy \& Continence Nursing, 39(3), 274-281.

5. Campbell, K. E., Woodbury, M. G., \& Houghton, P. E. (2010). Implementation of best practice in the prevention of heel pressure ulcers in the acute orthopedic population. International wound journal, 7(1), 28-40.

6. Coleman, S., Gorecki, C., Nelson, E. A., Closs, S. J., Defloor, T., Halfens, R., ... \& Nixon, J. (2013). Patient risk factors for pressure ulcer development: systematic review. International journal of nursing studies, 50(7), 974-1003.

7. Cox, J. (2011). Predictors of pressure ulcers in adult critical care patients. American journal of critical care, 20(5), 364-375.

8. de Oliveira Matos, S. D., Diniz, I. V., de Lucena, A. L. R., da Costa Andrade, S. S., de Brito, K. K. G., de Aguiar, E. S. S., ... \& da Silva, M. A. (2017). Pressure Ulcers in Institutionalized Elderly People: Association of Sociodemographic and Clinical Characteristics and Risk Factors. Open Journal of Nursing, 7(01), 111.

9. Durkin, D. \& May, R. (2015). Stop the Pressure, available at http://nhs.stop the pressure.co.uk/whatshappening.html. Retrieved on April 20, 2017.

10. Inan, D. G., \& Öztunç, G. (2012). Pressure ulcer prevalence in Turkey: a sample from a university hospital. Journal of Wound Ostomy \& Continence Nursing, 39(4), 409413.

11. Jaeblon, T. (2010). Pressure ulcers in orthopaedics. Journal of the American Academy of Orthopaedic Surgeons, 18(9), 568-575.

12. Krapfl, L. A., \& Gray, M. (2008). Does regular repositioning prevent pressure ulcers?. Journal of Wound Ostomy \& Continence Nursing, 35(6), 571-577.

13. Kwong, E. W., Hung, M. S., \& Woo, K. (2016). Improvement of pressure ulcer prevention care in private for-profit residential care 
homes: an action research study. BMC geriatrics, 16(1), 192.

14. Levine, S. M., Sinno, S., Levine, J. P., \& Saadeh, P. B. (2013). Current thoughts for the prevention and treatment of pressure ulcers: using the evidence to determine fact or fiction. Annals of surgery, 257(4), 603-608.

15. Lindgren, M., Unosson, M., Krantz, A. M., \& Ek, A. C. (2005). Pressure ulcer risk factors in patients undergoing surgery. Journal of advanced nursing, 50(6), 605-612.

16. Moore, Z., \& Dealey, C. (2014). Focus on tissue viability. International Journal of Orthopaedic and Trauma Nursing, 18(3), 119-121.
17. Ratliff, C. R., Tomaselli, N., Goldberg, M., Bonham, P., Crawford, P. S., Flemister, B. G., ... \& Palmer, R. (2010). WOCN update on evidence-based guideline for pressure ulcers. Journal of Wound Ostomy \& Continence Nursing, 37(5), 459-460.

18. Tsaras, K., Chatzi, M., Kleisiaris, C. F., Fradelos, E. C., Kourkouta, L., \& Papathanasiou, I. V. (2016). Pressure Ulcers: Developing Clinical Indicators in Evidence-based Practice. A Prospective Study. Medical Archives, 70(5), 379.

19. Yusuf, S., Okuwa, M., Shigeta, Y., Dai, M., Iuchi, T., Rahman, S., ... \& Sanada, H. (2015). Microclimate and development of pressure ulcers and superficial skin changes. International wound journal, 12(1), 40-46. 